\title{
슬개대퇴통증증후군 환자의 체중부하운동 유형별 하지 근활성량의 차이*
}

\author{
안근옥 ${ }^{1)} \cdot$ 조지훈 $)^{* *}$
}

1) 단국대학교 2) 신경대학교

\begin{abstract}
Keun-Ok An · ji-Hoon Cho. The Difference of Electromyographic Activity of Lower Extremity among Weight-bearing Exercises in Patients with Patellofemoral Pain Syndrome. KINESIOLOGY, 2015, 17(4): 49-56. [PURPOSE] The purpose of this study was to investigate analysis of difference of electromyographic activity on rectus femoris(RF), vastus medialis oblique(VMO), vastus lateralis(VL) and gluteus medius(GM) on type of weight-bearing in patients with patellofemoral pain syndorme. [METHODS] The subjects of this study were 13 female patients with patellofemoral pain syndorme 16 case(Right 8 case, Left 8 case) who are 20 - 30 years. The subjects of the study were rectus femoris, vastus medialis oblique, vastus lateralis and gluteus medius attached EMG electrodes to measure the electromyographic activity during weight-bearing exercise. Weight-bearing exercise was conducted half squat(HS), wall half squat(WHS), pillow wall half squat(PWHS) and single lim wall squat(SLWS). The investigator measured and analyzed the factors related to $\mathrm{EEMG}$ of muscle and electromyographic activity ratio during four type weight-bearing exercise the experiment collected data through measures of one-way ANOVA with the statistical significance level set at $a=.05$. [RESULTS] Weight-bearing exercise effective way to increase muscle activation of the VMO during weight-bearing eccentric contraction was shown to SLWS, weight-bearing exercise effective way to increase muscle activation of the GM were to PWHS. Second, weight-bearing exercise effective way to increase muscle activation of the GM during weight-bearing isometric contraction was shown to WHS and PWHS. Third, the weight-bearing concentric contraction of muscles during four kinds of effective weight-bearing exercise to increase muscle activation of specific muscles were not. [CONCLUSIONS] This study the results of the four type weight-bearing exercise according to the class of muscle contraction in the muscle activity with PFPS patients through each muscle was confirmed that the most efficient forms of exercise.
\end{abstract}

Key words : patellofemoral pain syndrome, muscle contraction type, weight-bearing, electromyographic activity 주요어 : 슬개대퇴통증증후군, 근수축 유형, 체중부하, 근활성

\section{서론}

슬개대퇴통증증후군(patellofemoral pain syndrome; $\mathrm{PFPS}$ )은 일반인뿐만 아니라 활동이 많은 사람들에게 호발하며(Almeida et al., 1999; Witvrouw et al., 2000), 특히 여성이 남성보다 2 배 이상 더 많이 나타나는 것 으로 보고되었다(Robinson, 2007).

PFPS는 무릎뼈 주변 또는 무릎 앞쪽으로 통증이 나타나기 때문에 앞면무릎통증(anterior knee pain)이 나 무릎주변통증(peripatella pain) 등 여러 가지 다른 이름으로 불리며 다양한 형태의 통증으로 나타난다
(Cerny, 1995, Chesworth et al., 1989).

PFPS의 원인이 매우 다양하지만 근육을 중심으로 살펴보면 안쪽넓은근(vastus medialis oblique; VMO) 의 근육약화, 가쪽넓은근(vastus lateralis; $\mathrm{VL}$ )에 대한 안쪽넓은근의 근육 불균형으로 인한 동적 불안정성, 무릎을 펼 때 근육 수축 시작시간의 지연이 무릎뼈의 비정상적인 가쪽 당김(lateral tracking)을 일으키는 원 인으로 알려져 있다(Pal et al., 2011; Shelton \& Thigpen, 1991). 또한 VMO보다 상대적으로 강한 엉덩 정강근막띠(iliotibial band)와 VL의 장력이 무릎빼 가 쪽 당김의 원인이 된다(Earl et al., 2001). PFPS가 없

\footnotetext{
* 이 논문은 2013년 정부(교육부)의 재원으로 한국연구재단의 지원을 받아 수행된 연구임(NRF-201351A5B5A07047742).

** 교신저자: jhchopro@hanmail.net
} 
는 경우 $\mathrm{VMO}: \mathrm{VL}$ 비율은 약 1:1이 가장 이상적이라고 하였다(Souza \& Gross, 1991). 그러나, PFPS 환자의 경우 $\mathrm{VMO}: \mathrm{VL}$ 비율이 1:1.85로 $\mathrm{VMO}$ 에 비해 $\mathrm{VL}$ 의 근 활성도가 더 크다고 하였고(Powers, 2000), 마찬가지로 등척성 무릎 폄 시 $\mathrm{VL}$ 에 대한 $\mathrm{VMO}$ 의 근활성도가 정 상인과 비교하여 낮다고 하였다(Makhsous et al., 2004). 이렇듯 넙다리네갈래근 각각의 비율은 PFPS와 매우 밀접한 관련이 있으므로 이들 각 근육의 활성도 에 대한 연구가 활발하게 이루어지고 있다.

또 다른 연구에 의하면, PFPS 환자들은 정상인들에 비하여 엉덩관절의 벌림근(hip abductor)과 가쪽돌림근 (hip external rotator)의 약화가 나타나고 있으며 (Baldon et al., 2009), 이로 인하여 엉덩관절의 안정성 이 떨어지는 경우에는 대퇴골의 모음과 안쪽돌림이 야 기되어 밖굽이무릎(valgus)과 목말밑관절(subtalar joint) 의 엎침(pronation)을 발생시켜 PFPS나 엉덩정강근막띠 증후군을 발생시킬 수 있다고 하였다(Ireland et al., 2003; Ford et al., 2005). 또한 중간볼기근(gluteus medius; GM)의 기능상 문제가 있거나 근활성도가 낮 은 경우에는 Q각(Q-angle)이 증가하여 밖굽이무릎을 유도하며, 무릎뼈를 가쪽으로 향하게 하는 방향량 (vector)이 증가하게 되어 무릎뼈 가쪽 당김을 발생시 킨다고 하였다(Earl et al., 2001).

PFPS 환자들을 대상으로 엉덩관절 벌림과 가쪽돌 림 근육을 중점적으로 6주간 근력운동을 실시한 결과 환자들의 통증 개선과 함께 중간볼기근의 근활성도가 증가되었다고 보고하였으며(Nakagawa et al., 2008), 정상인을 대상으로 한발 스쿼트와 양발 스쿼트를 비교 한 또 다른 연구에서는 한발 스쿼트가 양발 스쿼트보 다 중간볼기근의 근활성도가 높았으며(Krause et al., 2009), 체중부하(weight bearing)운동이 비체중부하 (non weight bearing)운동보다 중간볼기근의 근활성도 가 높게 나타났다고 보고하였다(Bolga \& Uhl, 2005).

지금까지의 선행연구들을 종합해 볼 때 PFPS는 전 체 하지근력의 약화가 문제가 아니라, 엉덩관절 및 슬 개대퇴에 작용하는 각 근육군의 불균형으로 생기는 문 제로 각 근육군의 역할이 매우 중요함을 알 수 있다.

현재까지의 선행 연구는 PFPS와 관련하여 대표적 으로 의미가 있는 안쪽넓은근과 가쪽넓은근의 비율과 중간볼기근의 근활성도에 대한 연구를 PFPS가 없는
건강한 피험자를 대상으로 실시한 경우가 대부분이다. 이러한 관점에서 볼 때, 실제 PFPS를 진단받은 환자 를 대상으로 넙다리곧은근, 안쪽넓은근, 가쪽넓은근, 그리고 중간볼기근의 근활성량의 비율 관계를 전체적 으로 동시에 조사하여 분석할 필요가 있다.

따라서 이 연구에서는 체중부하운동 시 중간볼기근 의 활성도가 다른 근육에 비해 더 높다는 선행연구를 바탕으로 하여 PFPS 환자를 대상으로 다양한 체중부 하운동 유형에 따라 근수축 방법별로 넙다리곧은근, 안쪽넓은근, 가쪽넓은근 및 중간볼기근의 근활성량 차 이를 알아보고자 실시하였다.

\section{연구방법}

\section{연구대상}

이 연구의 대상은 정형외과 전문의에게서 PFPS로 진단받은 20 30대 여성환자 13명의 무릎 16예(오른쪽 8, 왼쪽 8)로 하였다.

이들 환자는 사전 X-Ray 판독에서 해부학적 이상 이 없었으며 실험의 목적과 운동검사의 방법에 관한 설명을 듣고 자발적으로 동의서에 서명하여 실험참여 의사를 밝힌 환자들로 하였다.

환자의 안전을 위해 모든 실험의 구성 및 진행은 담 당주치의와 사전 논의 후 실시하였으며, 실험 중 통증을 유발하는 등 이상 징후가 관찰될 경우 대상에서 제외시 켰다. 피험자들의 신체적 특성은 <Table 1>과 같다.

Table 1. Physical characteristic of subjects ( $M \pm S D)$

\begin{tabular}{cccc}
\hline age $(\mathrm{yrs})$ & height $(\mathrm{cm})$ & weight $(\mathrm{kg})$ & $\mathrm{BM}\left(\mathrm{kg} / \mathrm{m}^{2}\right)$ \\
\hline \hline $30.00 \pm 4.87$ & $162.25 \pm 6.79$ & $53.38 \pm 9.56$ & $20.16 \pm 2.63$ \\
\hline
\end{tabular}

\section{실험 절차}

피험자들은 반바지를 착용한 후 신체측정을 실시하 였고 근전도 측정을 위한 전극을 부착하였다. 이후 네 가지 유형의 체중부하운동을 실시하였고 동작에 따른 근활성량을 측정하였다. 


\section{연구 장비}

동작에 따른 근활성량 측정을 위하여 표면근전도 측정 시스템(PolyGA, LAXTHA, 한국)을 활용하였다. 표면 양극전극(bipolar electrode)을 사용하였으며 양 극간의 거리는 $1 \mathrm{~cm}$ 로 하였다. 근전도 신호는 $1024 \mathrm{~Hz}$ 의 속도로 측정하였으며 실험 오류(technical fault)의 발생을 최소화하기 위하여 표면 전극을 붙이기 전 피 부를 에틸 알콜솜으로 닦았다. 근활성량 측정을 위한 전극은 넙다리곧은근(rectus femoris; RF), 안쪽넓은근 (vastus medialis oblique; $\mathrm{VMO}$ ), 가쪽넓은근(vastus lateralis; $\mathrm{VL}$ )과 중간볼기근(gluteus medius; $\mathrm{GM}$ )에 부착 하였다<Table 2>.

Table 2. EMG electrode placement

\begin{tabular}{cl}
\hline muscle & electrode placement \\
\hline \hline rectus & At $50 \%$ on the line from the anterior spina \\
femoris & iliaca superior to the superior part of the patella \\
\hline vastus At $80 \%$ on the line between the anterior spina \\
medialis iliaca superior and the joint space in front of \\
oblique the anterior border of the medial ligament. \\
\hline vastus At $2 / 3$ on the line from the anterior spina \\
lateralis iliaca superior to the lateral side of the patella. \\
\hline gluteus At $50 \%$ on the line from the crista iliaca to \\
medius the trochanter
\end{tabular}

\section{체중부하운동}

운동을 시작하기 전 피험자에게 4 가지 유형의 체중 부하운동 동작을 교육하였으며, 체중부하 운동을 통해 근전도 신호를 측정할 때 운동 순서에 따른 효과를 배 제하기 위하여 운동 순서를 무작위로 선정하였다. 운동 을 시작하기 전 모든 피험자는 하지근육의 스트레칭을 실시하였다. 4 가지 유형의 운동을 각 2회 실시하고 신 장성 수축(하강)을 3 초에 걸쳐 실시하고 등척성 수축 (하강한 후 멈춤)을 2 초에 걸쳐 실시하고 단축성 수축 (상승)을 3 초에 걸쳐 실시하여 총 8 초를 실시하였으며 각 세트 간 휴식시간을 2 분으로 정하여 근피로를 최소 화하였다. 체중부하운동의 4 가지 유형은 하프 스쿼트 (half squat; HS), 월 하프 스쿼트(wall half squat; WHS), 모음근 강화 월 하프 스쿼트(pillow wall half squat; PWHS), 한발 월 스쿼트(single leg wall squat; SLWS)를 실시하였고, 운동방법은 다음과 같다.

\section{하프 스쿼트(half squat)}

$\mathrm{HS}$ 는 앉기 동작 시 각도계를 이용하여 피험자의 무릎관절이 $45^{\circ}$ 굽힘되도록 하되 무릎뼈의 중심이 발 의 두 번째 발가락을 향하도록 하였다. 각도계의 축은 무릎관절의 회전축에 위치하고 고정팔은 넙다리뼈의 큰돌기를 기준으로 넙다리뼈의 가쪽 중앙에 위치하며 움직임 팔은 하퇴의 중앙에 가쪽 복사뼈와 종아리뼈 머리에 위치시켰다.

\section{월 하프 스쿼트(wall half squat)}

WHS는 $\mathrm{HS}$ 와 동일한 방법으로서 다른 점은 운동 이 수행되는 동안 피험자는 벽에 기대고 실시하며 넙 다리뼈와 정강뼈가 중립자세로 수직을 유지할 수 있 도록 교육 하였다.

\section{모음근 강화 월 하프 스쿼트(pillow wall half squat)}

$\mathrm{PWHS}$ 는 WHS와 동일한 운동방법이지만, 추가적 으로 운동이 수행되는 동안 등척성 모음을 유지하였 다. 등척성 모음을 효율적으로 적용하기 위해 양쪽 무 릎빼 사이에 베개를 두고 떨어지지 않도록 모음 수축 동작을 실시하도록 하였다.

\section{한발 스쿼트(single leg wall squat)}

SLWS는 WHS와 동일한 운동방법이지만, PFPS이 있는 한 쪽 다리로만 실시하고 반대 쪽 다리는 들어 올려 지면과 떨어진 상태로 운동을 실시하였다.

\section{결과 산출 방법}

네 가지 체중부하 운동 방법에 따른 각 근육의 근활 성량은 측정된 표면근전도 신호를 실효값(root mean square; RMS) 처리한 휘(Gary \& Loretta, 2000) 동작별 구 간을 나누어 적분근전도(integral $\mathrm{EMG} ; \mathrm{iEMG)}$ 를 계산하 였다. 신장성 수축은 하강하는 3 초의 시간 중에서 0.5 초부 터 25초까지 2초간의 iEMG 값을 채택하였고, 등척성 수 축은 하강 후 멈춰있는 2 초의 시간 중에서 0.5 초부터 1.5 초까지 1 초간의 $\mathrm{iEMG}$ 값을 채택하였다. 단축성 수축은 상승하는 3 초의 시간 중 0.5 초부터 2.5 초까지 2 초간의 $\mathrm{iEMG}$ 값을 채택하였다. 피험자별 2회 측정의 평균값을 자료 분석에 사용하였으며, 각 근육간의 근활성량 비교는 
1) 넙다리곧은근에 대한 안쪽넓은근, 가쪽넓은근, 중간볼 기근의 비율( $\mathrm{VMO} / \mathrm{RF}, \mathrm{VL} / \mathrm{RF}, \mathrm{GM} / \mathrm{RF})$, 2) 안쪽넓은근에 대한 가쪽넓은근, 중간볼기근, 넙다리곧은근의 비율 (VL/VMO, GM/VMO, RF/VMO), 3) 가쪽넓은근에 대한 중간볼기근, 안쪽넓은근, 넙다리곧은근의 비율 $(\mathrm{GM} / \mathrm{VL}$, $\mathrm{VMO} / \mathrm{VL}, \mathrm{RF} / \mathrm{VL})$ 을 백분율화 하여 분석하였다.

\section{통계처리}

이 연구의 모든 자료는 평균과 표준편차를 구하였다. 4 가지 유형의 체중부하운동시 각 근육의 $\mathrm{iEMG}$ 를 구하고 각 근육의 활성량 비율을 비교하기 위하여 일원배치분산 분석(one-way ANOVA)을 실시하였다. 각 근육의 활성량
비율에 유의한 차이가 있는 경우, 사후검정은 Bonferroni 방법을 사용하여 다중비교검증을 하였다. 통계적 유의성 을 검정하기 위해 유의수준( $(a)$ 은 .05로 정하였다.

\section{결과}

\section{신장성 수축시의 iEMG 비율(\%)}

신장성 수축시 HS, WHS, PWHS, SLWS에 따른 각 근육간의 활성량 비율은 <Table 3 과 같다.

$\mathrm{RF}$ 에 대한 $\mathrm{VMO}$ 의 비율(VMO/RF)은 운동 유형간 유 의한 차이가 있었고 $(p=.042)$ 사후검정결과, SLWS가 HS

Table 3. iEMG ratio according to weight-bearing type

$\%(\mathrm{M} \pm \mathrm{SD})$

\begin{tabular}{|c|c|c|c|c|c|c|c|c|}
\hline \multirow{2}{*}{ type } & \multicolumn{2}{|c|}{ ratio ${ }^{\dagger}$} & \multirow{2}{*}{ HS } & \multirow{2}{*}{ WHS } & \multirow{2}{*}{ PWHS } & \multirow{2}{*}{ SLWS } & \multirow{2}{*}{$p$} & \multirow{2}{*}{ post-hoc } \\
\hline & $\mathrm{a}$ & $\mathrm{b}$ & & & & & & \\
\hline \multirow{9}{*}{ EC } & \multirow{3}{*}{$\mathrm{RF}$} & $\mathrm{VMO}$ & $103.18 \pm 10.46$ & $112.38 \pm 11.19$ & $107.10 \pm 11.45$ & $116.62 \pm 20.02$ & $.042^{*}$ & $\mathrm{HS}<\mathrm{SLWS}$ \\
\hline & & VL & $101.51 \pm 18.74$ & $102.73 \pm 12.60$ & $107.68 \pm 26.78$ & $106.94 \pm 21.11$ & .785 & - \\
\hline & & GM & $75.38 \pm 8.03$ & $83.26 \pm 6.47$ & $82.69 \pm 14.28$ & $73.58 \pm 14.45$ & $.036^{*}$ & - \\
\hline & \multirow{3}{*}{$\mathrm{VMO}$} & VL & $98.78 \pm 17.11$ & $92.33 \pm 14.75$ & $100.49 \pm 20.23$ & $92.59 \pm 13.60$ & .388 & - \\
\hline & & GM & $73.66 \pm 9.86$ & $74.66 \pm 8.21$ & $78.10 \pm 16.32$ & $64.46 \pm 14.90$ & $.025^{*}$ & SLWS $<$ PWHS \\
\hline & & $\mathrm{RF}$ & $97.83 \pm 9.96$ & $94.32 \pm 9.52$ & $88.26 \pm 16.17$ & $89.86 \pm 9.49$ & .094 & - \\
\hline & \multirow{3}{*}{ VL } & GM & $75.96 \pm 12.87$ & $81.83 \pm 8.91$ & $79.90 \pm 18.53$ & $69.92 \pm 14.31$ & .094 & - \\
\hline & & $\mathrm{VMO}$ & $103.81 \pm 16.48$ & $102.81 \pm 17.94$ & $110.15 \pm 15.78$ & $110.91 \pm 17.65$ & 409 & - \\
\hline & & $\mathrm{RF}$ & $101.08 \pm 15.40$ & $96.74 \pm 17.35$ & $95.98 \pm 13.84$ & $98.63 \pm 11.24$ & .764 & - \\
\hline \multirow{9}{*}{ IS } & \multirow{3}{*}{$\mathrm{RF}$} & $\mathrm{VMO}$ & $115.98 \pm 18.46$ & $115.74 \pm 14.32$ & $118.46 \pm 14.59$ & $122.87 \pm 17.11$ & .577 & - \\
\hline & & VL & $107.61 \pm 16.88$ & $98.73 \pm 7.39$ & $108.44 \pm 18.73$ & $114.13 \pm 27.29$ & .156 & - \\
\hline & & GM & $56.41 \pm 10.92$ & $72.74 \pm 7.08$ & $77.01 \pm 18.85$ & $64.54 \pm 12.31$ & $.000^{* \star *}$ & $\mathrm{HS}<\mathrm{WHS}, \mathrm{HS}<\mathrm{PWHS}$ \\
\hline & \multirow{3}{*}{ VMO } & VL & $94.54 \pm 18.88$ & $86.73 \pm 13.87$ & $92.66 \pm 18.61$ & $94.33 \pm 24.32$ & .633 & - \\
\hline & & GM & $50.06 \pm 13.14$ & $64.04 \pm 11.54$ & $65.76 \pm 17.44$ & $53.49 \pm 12.21$ & $.003^{* *}$ & $\mathrm{HS}<\mathrm{WHS}, \mathrm{HS}<\mathrm{PWHS}$ \\
\hline & & $\mathrm{RF}$ & $88.49 \pm 15.57$ & $85.52 \pm 9.78$ & $83.03 \pm 12.72$ & $87.69 \pm 11.13$ & .608 & - \\
\hline & \multirow{3}{*}{ VL } & GM & $53.91 \pm 14.36$ & $74.09 \pm 9.01$ & $73.00 \pm 21.47$ & $58.35 \pm 13.76$ & $.000^{\star \star \star *}$ & $H S<W H S, H S<P W H S, S L W S<W H S$ \\
\hline & & VMO & $109.44 \pm 19.78$ & $111.78 \pm 21.25$ & $111.36 \pm 23.32$ & $118.09 \pm 18.85$ & .671 & - \\
\hline & & $\mathrm{RF}$ & $95.06 \pm 14.71$ & $94.41 \pm 14.10$ & $90.89 \pm 15.41$ & $101.84 \pm 7.93$ & .143 & - \\
\hline \multirow{9}{*}{$\mathrm{CO}$} & \multirow{3}{*}{$\mathrm{RF}$} & $\mathrm{VMO}$ & $108.84 \pm 16.87$ & $117.98 \pm 25.65$ & $112.23 \pm 13.48$ & $120.96 \pm 18.09$ & .275 & - \\
\hline & & VL & $107.77 \pm 27.97$ & $102.37 \pm 13.66$ & $110.94 \pm 23.69$ & $110.74 \pm 23.52$ & .690 & - \\
\hline & & GM & $68.74 \pm 12.90$ & $71.31 \pm 8.12$ & $73.07 \pm 14.30$ & $70.12 \pm 11.58$ & .770 & - \\
\hline & \multirow{3}{*}{ VMO } & $\mathrm{VL}$ & $100.03 \pm 26.59$ & $89.19 \pm 16.76$ & $101.45 \pm 31.97$ & $92.76 \pm 21.19$ & .451 & - \\
\hline & & GM & $64.88 \pm 16.76$ & $62.29 \pm 10.89$ & $65.58 \pm 12.33$ & $59.39 \pm 14.18$ & .572 & - \\
\hline & & $\mathrm{RF}$ & $94.11 \pm 15.61$ & $90.43 \pm 12.06$ & $84.36 \pm 12.30$ & $88.43 \pm 19.01$ & .327 & - \\
\hline & \multirow{3}{*}{ VL } & GM & $67.20 \pm 21.36$ & $70.81 \pm 11.24$ & $68.08 \pm 16.58$ & $64.85 \pm 12.94$ & .769 & - \\
\hline & & VMO & $104.36 \pm 18.51$ & $104.84 \pm 21.63$ & $112.01 \pm 20.65$ & $116.21 \pm 23.98$ & .329 & - \\
\hline & & $\mathrm{RF}$ & $97.46 \pm 21.49$ & $92.79 \pm 13.51$ & $93.31 \pm 15.67$ & $100.29 \pm 21.01$ & .612 & - \\
\hline
\end{tabular}

EC; eccentric contraction, IS; isometric contraction, CO; concentric contraction, $\dagger^{(b / a) \times 100, ~ H S ; ~ h a l f ~ s q u a t, ~ W H S ; ~ w a l l ~ h a l f ~ s q u a t, ~ P W H S ; ~ p i l l o w ~}$ wall half squat, SLWS; single leg wall squat, RF; rectus femoris, VMO; vastus medialis oblique, VL; vastus lateralis, GM; gluteus medius ${ }^{*} p<.05,{ }^{* *} p<.01,{ }^{* * *} p<.001$ 
보다 유의하게 더 높았다 $(p=048)$. GM도 유의한 차이가 있었으나 $(p=.036)$ 뚜렷한 차이는 없었고, $\mathrm{RF}$ 에 대한 $\mathrm{VL}$ 의 비율(VL/RF)은 운동 유형간 유의한 차이가 없었다.

$\mathrm{VMO}$ 에 대한 $\mathrm{GM}$ 의 비율(GM/VMO)은 운동 유형 간 유의한 차이가 있었고 $(p=.025)$ 사후검정결과 $\mathrm{PWHS}$ 가 SLWS보다 유의하게 더 높았다( $p=.048)$. $\mathrm{VMO}$ 에 대 한 $\mathrm{VL}, \mathrm{RF}$ 의 비율(VL/VMO, RF/VMO)은 운동 유형 간 유의한 차이가 없었다.

$\mathrm{VL}$ 에 대한 $\mathrm{GM}, \mathrm{VMO}, \mathrm{RF}$ 의 비율(GM/VL, $\mathrm{VMO} / \mathrm{VL}$, $\mathrm{RF} / \mathrm{VL})$ 은 운동 유형간 유의한 차이가 없었다.

따라서, $\mathrm{PFPS}$ 환자가 신장성 수축시 $\mathrm{VMO}$ 의 근활성 량 비율이 가장 큰 방법은 SLWS로 나타났으며, GM의 근활성량 비율이 가장 큰 방법은 PWHS로 나타났다.

\section{등척성 수축시의 iEMG 비율(\%)}

등척성 수축시 $\mathrm{HS}, \mathrm{WHS}, \mathrm{PWHS}, \mathrm{SLWS}$ 에 따른 각 근육간의 활성량 비율은 <Table 3>과 같다.

$\mathrm{RF}$ 에 대한 $\mathrm{GM}$ 의 비율(GM/RF)은 운동 유형간 유의한 차이가 있었고 $(p=.000)$ 사후검정결과, WHS가 $\mathrm{HS}$ 보다 유 의하게 더 높았고 $(p=.005), \mathrm{PWHS}$ 가 HS보다 유의하게 더 높았다 $(p=.000)$. $\mathrm{RF}$ 에 대한 $\mathrm{VMO}, \mathrm{VL}$ 의 비율 $(\mathrm{VMO} / \mathrm{RF}$, $\mathrm{VL} / \mathrm{RF}$ )은 운동 유형간 유의한 차이가 없었다.

$\mathrm{VMO}$ 에 대한 $\mathrm{GM}$ 의 비율(GM/VMO)은 운동 유형 간 유의한 차이가 있었고 $(p=.003)$ 사후검정결과, $\mathrm{WHS}$ 가 $\mathrm{HS}$ 보다 유의하게 더 높았고( $p=.034), \mathrm{PWHS}$ 가 HS 보다 유의하게 더 높았다( $p=.012) . \mathrm{VMO}$ 에 대한 $\mathrm{VL}$, $\mathrm{RF}$ 의 비율(VL/VMO, $\mathrm{RF} / \mathrm{VMO})$ 은 운동 유형간 유의 한 차이가 없었다.

$\mathrm{VL}$ 에 대한 $\mathrm{GM}$ 의 비율(GM/VL)은 운동 유형간 유의 한 차이가 있었고 $(p=.000)$ 사후검정결과, WHS가 HS보다 유의하게 더 높았고( $p=.003), \mathrm{PWHS}$ 가 HS보다 유의하게 더 높았으며 $(p=.005), \mathrm{WHS}$ 가 SLWS보다 유의하게 더 높 았다 $(p=.031)$. $\mathrm{VL}$ 에 대한 $\mathrm{VMO}, \mathrm{RF}$ 의 비율 $(\mathrm{VMO} / \mathrm{VL}$, $\mathrm{RF} / \mathrm{VL})$ 은 운동 유형간 유의한 차이가 없었다.

따라서, PFPS환자가 등척성 수축시 $\mathrm{GM}$ 의 근활성량 비율이 가장 큰 방법은 WHS와 PWHS로 나타났다.

\section{단축성 수축시의 iEMG 비율(\%)}

단축성 수축시 $\mathrm{HS}, \mathrm{WHS}, \mathrm{PWHS}, \mathrm{SLWS}$ 에 따른 각 근육간의 활성량 비율은 < Table 3>과 같다.

각 근육간의 활성량 비율은 어떠한 운동 유형간에 도 유의한 차이가 없었다. 따라서, PFPS환자가 단축성 수축시 4 가지 근육 중 특정 근육의 근활성량이 가장 큰 체중부하운동은 없는 것으로 나타났다.

\section{논의}

이 연구는 PFPS 환자를 대상으로 다양한 체중부하 운동 유형에 따른 근수축 방법별로 $\mathrm{RF}, \mathrm{VMO}, \mathrm{VL}$ 및 $\mathrm{GM}$ 의 근활성량 차이를 알아보기 위하여 실시하였다.

신장성 수축 시 다양한 체중부하운동 유형에 따른 각 근육의 비율을 조사한 결과 $\mathrm{VMO}$ 의 근활성 비율 을 가장 높이는 체중부하운동 유형은 SLWS로 나타났 으며, $\mathrm{GM}$ 의 근활성 비율을 가장 높이는 체중부하운 동 유형은 PWHS로 나타났다.

먼저 $\mathrm{VMO}$ 근활성화가 중요한 이유는 PFPS 환자는 상대적으로 $\mathrm{VL}$ 의 근활성도가 높고(Makhsous, et al., 2004; Powers, 2000), $\mathrm{VMO}$ 의 약화가 PFPS의 주된 원인 이기 때문이다(Earl et al., 2001; Ng et al., 2008). VMO 가 약화되면 무릎관절의 폄 시 $\mathrm{VL}$, 엉덩정강근막띠에 의 해 무릎빼가 가쪽으로 아탈구 될수 있고(Francis \& Scott, 1974; Speakman \& Weisburg, 1977), 슬개대퇴에 부정적 인 영향을 미치게 되므로 $\mathrm{VMO}$ 의 강화가 PFPS의 적합 한 치료 방법이라고 하였다(Laprade et al., 1998).

이 연구 결과는 PFPS 환자를 대상으로 했음에도 불구하고 4 가지 체중부하운동 유형 모두에서 VL에 대한 $\mathrm{VMO}$ 의 근활성량 비율이 더 높게 나타났다. 이 연구와 유사하게 체중부하 30도 굽힘 미니 스쿼트에 서 $\mathrm{VMO}: \mathrm{VL}$ 근전도 비율이 좌측 $1.02 \pm 0.30$ 우측 $1.28 \pm 0.59$ 로 $\mathrm{VL}$ 에 대한 $\mathrm{VMO}$ 의 근활성 비율이 더 높 게 나타났다(Earl et al., 2001). 이 연구 결과와는 상 반되게 다른 연구에서는 $\mathrm{VL}$ 에 대한 $\mathrm{VMO}$ 의 근활성 비율이 더 낮게 나타난 결과도 있다(Makhsous, et al., 2004; Powers, 2000). 이렇게 상반된 결과를 나타낸 
이유는 체중부하를 하지 않은 앉은 자세에서 60 도 무 릎 굽힘하고 근활성도를 측정하였고(Makhsous, et al., 2004), 또 다른 연구 또한 체중부하를 하지 않은 엎드 린 자세로 무릎 0 도, 9도, 18 도, 27 도, 36 도 45 도에서 등척성 근력의 평균값으로 근활성도를 측정하였기 때 문이다(Powers, 2000). 따라서 체중부하의 유무가 VL 에 대한 $\mathrm{VMO}$ 를 활성화의 높고 낮음을 결정하는 요 인이 됨을 알 수 있었고, 이 연구에서 시행한 4 가지 체중부하운동 유형 모두는 비체중부하 운동 유형에 비해 $\mathrm{VL}$ 에 대한 $\mathrm{VMO}$ 를 활성화 시키는 데 적합한 운동 유형이라고 할 수 있다.

$\mathrm{VMO}$ 활성화를 위한 운동방법으로 넙다리네갈래근 수축운동과 엉덩관절 모음을 동시에 시행하는 방법이 효과적이라고 보고되고 있다(Hanten et al., 1990; Monteiro-Pedro et al., 1999). 이와 관련하여 이 연구 에서는 신장성 수축시 SLWS가 $\mathrm{VMO}$ 를 선택적으로 강화하는데 가장 효율적인 방법으로 나타났다. 따라서 신장성 수축시 SLWS가 4가지 체중부하운동 유형 중 넙다리네갈래근과 엉덩관절 모음이 동시에 진행될 가 능성이 가장 높은 운동방법임을 시사한다. 그러나, 등 척성 수축시와 단축성 수축시 각 근육의 근활성량 비 율에서 $\mathrm{VMO}$ 를 선택적으로 강화하는 효율적인 체중부 하운동 유형은 나타나지 않았다. 이는 신장성 수축시 SLWS 실시가 등척성 수축시와 단축성 수축시의 근수 축 형태에 비해 $\mathrm{VMO}$ 의 근활성량 비율을 높일 수 있 는 운동 유형임을 간접적으로 나타낸다고 생각된다.

또한 이 연구에서 신장성 수축 시 $\mathrm{GM}$ 의 근활성량 비율이 SLWS 보다도 PWHS이 더 효율적인 것으로 나타난 것과 관련하여, Krause et al(2009)의 연구에서 $\mathrm{GM}$ 의 Peak EMG(\%MVIC)가 두 발 스쿼트를 시행 할 때 보다 한발 45 도 스쿼트에서 유의하게 높게 나 타났다고 보고하였다. 이러한 결과는 $\mathrm{GM}$ 의 근활성량 이 한발 스쿼트인 SLWS 보다 PWHS가 더 효율적이 라는 이 연구결과와 일치하는 것으로 나타났다. 또한, 이 연구에서 PFPS환자가 등척성 수축시 $\mathrm{GM}$ 의 근활 성화를 높이는 효율적인 체중부하운동방법은 WHS와 PWHS로 나타났다.

여러 선행연구에서 스쿼트 운동시 엉덩관절 등척성 모음의 병행이 $\mathrm{VMO}$ 를 선택적으로 더 활성화 시키지 는 못한다고 하였다(Coqueiro et al., 2005; Earl et al.,
2001; Hertel et al.,2004). 이러한 결과는 이 연구에서 스쿼트 운동시 엉덩관절 등척성 모음의 병행과 유사 한 등척성 운동시 PWHS 뿐만 아니라 다른 체중부하 운동 유형 중 $\mathrm{VMO}$ 를 선택적으로 활성화 시키는 체 중부하운동 유형이 나타나지 않은 것과 일치된다.

스쿼트 및 하프스쿼트 등의 체중부하 운동방법은 넙다리네갈래근육과 넙다리뒤근육의 동시 수축과 무 릎 관절에 대한 압력의 증가를 유도하여 앞정강 넙다 리 관절의 전위를 감소시킬 수 있고 고유수용성 기능 을 촉진시키는 것으로 알려져 있다(Coqueiro et al., 2005). 따라서 체중부하 운동방법은 PFPS 환자 뿐만 아니라 무릎의 재활운동에서 흔하게 권장되는 운동방 법으로 그 역할이 중요하다.

이 연구 결과 다양한 체중부하운동 유형 중 45 도 무릎 굽힘 상태에서 체중부하 등척성 운동을 실시했 을 경우 $\mathrm{GM}$ 활성화를 위한 효율적인 체중부하 운동 방법은 WHS와 PWHS로 나타났다. 이는 PFPS 환자 가 재활운동을 통해 $\mathrm{GM}$ 을 활성화 시켰을 때 증상의 호전이 있다는 연구결과(Nakagawa et al., 2008)에 비 추어 볼 때, $\mathrm{GM}$ 의 역할이 통증완화에 핵심적인 역할 을 하고 있는 것을 알 수 있고, 통증완화를 위한 효율 적인 체중부하 운동방법을 밝혔다는데 의미가 있다. 이러한 측면에서 이 연구 결과는 $\mathrm{GM}$ 의 근활성량을 증가시키는 방법으로 비체중부하(non weight bearing) 운동보다 체중부하(weight bearing)운동이 더 효율적 이라는 선행 연구(Bolga \& Uhl, 2005)와도 일치하는 것으로 체중부하 운동을 통한 PFPS의 해소를 기대할 수 있을 것이라 판단된다.

이상의 논의를 종합하면, PFPS은 발병 빈도가 높음 에도 불구하고 구조적으로 골격계나 연골의 문제가 나타나지 않는 경우가 대부분이고, 기계적 불안정성이 없다는 이유로 방치하는 경우가 많다. 그러나 PFPS 환자들의 주관적 통증정도는 실질적으로 일상생활에 막대한 지장을 초래할 만큼 통증과 불편함을 느끼고 있다. 이를 해결하기 위한 첫 번째 열쇠는 수술 등의 침습적인 방법이 아니라 보존적인 방법으로 근육의 균형을 회복하는 것이 절대적으로 필요하다. 


\section{결론 및 제언}

본 연구 결과를 통해 PFPS 환자의 4 가지 체중부하 운동 유형에 따라 근수축 방법별로 각 근육의 근활성 량 수준을 확인할 수 있었다.

결론적으로 신장성 수축의 경우 $\mathrm{VMO}$ 의 근활성 비율 을 가장 높이는 운동 유형은 SLWS로 나타났고, GM의 근활성 비율을 가장 높이는 운동 유형은 PWHS로 나타 났다. 또한 등척성 수축의 경우 $\mathrm{GM}$ 의 근활성 비율을 가 장 높이는 운동 유형은 WHS와 PWHS로 나타났다.

따라서 추후 연구에서는 본 연구에서 확인한 근활 성량 비율을 참고하여 선택한 근육강화 재활 운동이 PFPS 환자에게 어느 정도 증상 호전에 기여할 것인 가를 단기적 또는 장기적으로 예측해 볼 필요가 있다.

\section{참고문헌}

Almeida, S. A., Williams, K. M., Shaffer, R. A., \& Brodine, S. K. (1999). Epidemiological patterns of musculoskeletal injuries and physical training. Medicine and Science in Sports and Exercise, 31(8): 1176-1182.

Baldon, R. M., Nakagawa, T. H., Muniz, T. B., Amorim, C. F., Maciel, C. D., \& Serrão, F. V.(2009). Eccentric hip muscle function in females with and without patellofemoral pain syndrome. Journal of athletic Training, 44(5): 490-496.

Bolga, L. A., \& Uhl, T. L.(2005). Electromyographic analysis of hip rehabilitation exercises in a group of healthy subjects. The Journal of orthopaedic and sports physical therapy, 35(8): 487-494.

Cerny, K. (1995). Vastus medialis oblique/vastus lateralis muscle activity ratios for selected exercises in persons with and without patellofemoral pain syndrome. Physical therapy. 75(8): 672-683.
Chesworth, B. M., Gulham, E. G., \& Tate, G. E. (1989). Validation of outcome measures in patients with patellofemoral syndrome. The Journal of orthopaedic and sports physical therapy, 10(8): 302-308.

Coqueiro, K R., Bevilaqua-Grossi, D., Bérzin, F., Soares, A. B., Candolo, C., \& Monteiro-Pedro, V. (2005). Analysis on the activation of the VMO and VLL muscles during semisquat exercises with and without hip adduction in individuals with patellofemoral pain syndrome. Journal of electromyography and kinesiology, 15(6): 596-603.

Earl, J. E., Schmitz, R. J., \& Arnold, B. L. (2001). Activation of the $\mathrm{VMO}$ and $\mathrm{VL}$ during dynamic mini-squat exercises with and without isometric hip adduction. Journal of electromyography and kinesiology, 11(6): 381-386.

Ford, K. R., Myer, G. D., Toms, H. E., \& Hewett, T. E. (2005). Gender differences in the kinematics of unanticipated cutting in young athletes. Medical Science Sport Exercise. 37(1): 124-129.

Francis, R. S, \& Scott, D. E. (1974). Hypertrophy of the vastus medialis in knee extension. Physical therapy, 54(10): 1066-1070.

Gary L S., \& Loretta M. K (2000). A guide for use and interpretation of kinesiologic electromyographic data. Physical therapy. 80(5): 485-498.

Hanten, W. P., \& Schulthies, S. S. (1990). Exercise effect on electromyographic activity of the vastus medialis oblique and vastus lateralis muscles. Physical therapy, 70(9): 561-565.

Hertel, J., Earl, J. E., Tsang, K. K., \& Miller, S. J. (2004). Combining isometric knee extension exercises with hip adduction or abduction does not increase quadriceps EMG activity. British journal of sports medicine, 38(2): 210-213.

Ireland, M. L., Wilson, J. D., Ballantyne, B. T., \& Davis, I. M. (2003). Hip strength in females with and without patellofemoral pain. The 
Journal of orthopaedic and sports physical therapy, 33(11): 671-676.

Krause, D. A., Jacobs, R. S., Pilger, K. E., Sather, B. R., Sibunka, S. P., \& Hollman, J. H. (2009). Electromyographic analysis of the gluteus medius in five weight-bearing exercises. Journal of strength and conditioning research, 23(9): 2689-2694.

Laprade, J., Culham, E., \& Brouwer, B. (1998). Comparison of five isometric exercises in the recruitment of the vastus medialis oblique in persons with and without patellofemoral pain syndrome. The Journal of orthopaedic and sports physical therapy, 27(3): 197-204.

Makhsous, M. Lin, F., Koh, J. L., Nuber, G. W., \& Zhang, L. Q. (2004). In vivo and noninvasive load sharing among the vasti in patellar malalignment. Medicine and science in sports and exercise. 36(10): 1768-1775.

Monteiro-Pedro, V., Vitti, M., Bérzin, F., \& Bevilaqua-Grosso, D. (1999). The effect of free isotonic and maximal isometric contraction exercises of the hip adduction on vastus medialis oblique muscle: an electromyographic study. Electromyography and clinical neurophysiology, 39(7): 435-440.

Nakagawa, T. H., Muniz, T. B., Baldon R. M., Maciel C. D., Reiff, R. M. \& Serrão F. V. (2008). The effect of additional strengthening of hip abductor and lateral rotator muscles in patellofemoral pain syndrome: a randomized controlled pilot study. Cinical rehabilitation, 22(12): 1051-1060.

Ng, G. Y., Zhang, A. Q., \& Li, C. K. (2008). Biofeedback exercise improved the EMG activity ratio of the medial and lateral vasti muscles in subjects with patellofemoral pain syndrome. Journal of electromyography and kinesiology, 18(1): 128-133.

Pal, S., Draper, C. E., Frederison, M, Gold, G. E., Delp, S. L., Beaupre, G. S., \& Besier, T. F. (2011). Patellar maltracking correlates with vastus medialis activation delay in patellofemoral pain patients. The American journal of sports medicine, 39(3): 590-598.

Powers, C. M. (2000). Patellar kinematics, Part I: The influence of vastus muscle activity in subjects with and without patellofemoral pain. Physical therapy, 80(10): 956-964.

Robinson, R. L., \& Nee, R. J. (2007). Analysis of hip strength in females seeking physical therapy treatment for unilateral patellofemoral pain syndrome. The Journal of orthopaedic and sports physical therapy, 37(5): 232-238.

Shelton, G. L., \& Thigpen, L. K. (1991). Rehabilitation of patellofemoral dysfunction: a review of literature. The Journal of orthopaedic and sports physical therapy, 14(6): 243-249.

Souza, D. R., \& Gross, M. T. (1991). Comparison of vastus medialis obliquus: vastus lateralis muscle integrated electromyographic ratios between healthy subjects and patients with patellofemoral pain. Physical therapy, 71(4): 310-320.

Speakman, H. G, \& Weisberg, J. (1977). The vastus medialis controversy. Physiotherapy, 63(8): 249-54

Witvrouw, E., Lysens, R., Bellemans, J., Cambier, D., \& Vanderstraeten, G. (2000). Intrinsic risk factors for the development of anterior knee pain in an athletic population. A two-year prospective. The American Journal of Sports Medicine, 28(4): 480-489. 